\title{
Faktor Risiko Skabies di Pondok Pesantren Konvensional dan Modern
}

\author{
Amanatun avidah ${ }^{1}$, Eko krisnarto ${ }^{1}$, Kanti Ratnaningrum ${ }^{1}$ \\ ${ }^{1}$ Fakultas Kedokteran Universitas Muhammadiyah Semarang
}

Email: kantiratna@unimus.ac.id

\begin{abstract}
Scabies is still a health problem and one of the diseases that often occur in Islamic boarding schools. Several previous studies have discussed the risk factors for scabies in Islamic boarding schools, hospitals, and working area of a primary health care, but no one has analyzed the risk factors for scabies in a number of Islamic boarding schools at the same time. An observational analytic study with case control design, simple random sampling technique, used primary data in the form of quesioner and examination to diagnosis of scabies. Analysis using the chi square test. From 190 samples obtained age 5.5 times increased risk of scabies $(\mathrm{OR}=5,531 ; 95 \% \mathrm{CI}=2,214-13,822)$, skin cleanliness 2.7 times increased risk of scabies $(\mathrm{OR}=2,715 ; 95 \%=1,223-6,027$ ), hand hygiene 2.5 times increased the risk of scabies $(\mathrm{OR}=2,499,95 \%=1,296-4,812)$, cleanliness of beds 3.5 times increased risk of scabies $(\mathrm{OR}=$ 3,$519 ; 95 \%=1,538-8,052$ ). Factors changing clothes, changing prayer equipment, cleaning clothes, and cleaning towels not significantly increase risk of scabies.
\end{abstract}

Keywords: scabies, personal hygiene, Islamic boarding school, risk factor

\section{Abstrak}

Scabies masih menjadi masalah kesehatan dan menjadi salah satu penyakit yang sering terjadi di lingkungan pondok pesantren. Beberapa penelitian sebelumnya telah membahas faktor risiko scabies pada pondok pesantren, rumah sakit, dan wilayah kerja sebuah puskesmas, tetapi belum ada yang menganalisis faktor risiko scabies pada beberapa pondok pesantren sekaligus, oleh karena itu peneliti ingin mengetahui faktor risiko skabies di pondok pesantren konvensional dan modern. Penelitian merupakan observasional analitik dengan desain case control, teknik simple random sampling. Penelitian menggunakan data primer berupa quesioner dan pemeriksaan untuk menentukan diagnosis scabies. Analisis menggunakan uji chi square. Dari 190 sampel di dapatkan hasil usia 5,5 kali meningkatkan risiko terjadinya scabies $(\mathrm{OR}=5.531 ; 95 \% \mathrm{CI}=2.214-13.822)$, kebersihan kulit 2,7 kali meningktakan risiko terjadinya scabies $(\mathrm{OR}=2.715 ; 95 \%=1.223-6.027)$, kebersihan tangan 2,5 kali meningkatkan risiko terjadinya scabies $(\mathrm{OR}=2.499,95 \%=1.296-4.812)$, kebersihan tempat tidur 3,5 kali meningkatkan risiko terjadinya scabies $(\mathrm{OR}=3.519 ; 95 \%=1.538$ - 8.052). Faktor berganti pakaian, berganti alat sholat, kebersihan pakaian, dan kebersihan handuk tidak signifikan meningktakan risiko terjadinya scabies.

Kata kunci : skabies, personal hygiene, pondok pesantren, faktor risiko

\section{PENDAHULUAN}

Skabies merupakan infeksi kulit yang disebabkan oleh Sarcoptes scabei var hominis beserta produknya ${ }^{1}$.

Scabies ditandai dengan gejala gatal di malam hari, terdapat terowongan pada tempat-tempat predileksi, ditemukan tungau Sarcoptes scabei pemeriksaan fisik. $^{2}$

Skabies banyak ditemukan pada tempat dengan penghuni padat seperti asrama tentara, penjara, dan pondok pesantren. Tempat hunian padat dan lingkungan yang kurang bersih mempercepat transmisi dan penularan skabies ${ }^{3}$

Prevalensi skabies di podok pesantren masih terbilang tinggi seperti di Pesantren An-Najach Magelang sebesar 43\%, ${ }^{4}$ di Pondok Pesantren AlBahroniyyah Ngemplak Demak sebesar 36,3\%, ${ }^{5}$ dan di salah satu pondok pesantren di Jakarta Timur sebesar $51,6 \%{ }^{6}$

Beberapa penelitian sebelumnya telah membahas faktor risiko scabies pada pondok pesantren, 
rumah sakit, dan wilayah kerja sebuah puskesmas, tetapi belum ada yang menganalisis faktor risiko scabies pada beberapa pondok pesantren sekaligus, oleh karena itu peneliti ingin mengetahui faktor risiko skabies di pondok pesantren konvensional dan modern.

\section{METODE PENELITIAN}

Penelitian merupakan observasional analitik dengan desain case control, dengan teknik simple random sampling. Penelitian menggunakan data primer berupa quesioner dan pemeriksaan fisik menggunakan dermatoskop untuk menentukan diagnosis scabies. Penelitian dilakukan di Pondok Pesantren Wasilatul Huda Kendal dan Pondok Pesantren Modern Selamat Kendal. Analisis menggunakan uji chi square.

Penelitian di lakukan setelah mendapat persetujuan dari komisi etik penelitian kesehatan (KEPK) Fakultas kedokteran muhammadiyah semarang dengan terbitkannya ethical clearance. NO.029/EC/FK/2019

\section{HASIL PENELITIAN}

Tabel 1. Distribusi Karakteristik Sampel

\begin{tabular}{|c|c|}
\hline Karakteristik sampel & $\mathrm{N}(\%)$ \\
\hline $\begin{array}{l}11-13 \text { tahun } \\
14-16 \text { tahun } \\
>17 \text { tahun }\end{array}$ & $\begin{array}{l}36(18.9) \\
89(46.8) \\
65(34.2)\end{array}$ \\
\hline $\begin{array}{c}\text { Bergantian Pakaian, } \\
\text { Tidak } \\
\text { Ya } \\
\end{array}$ & $\begin{array}{l}98(51.6) \\
92(48.4)\end{array}$ \\
\hline $\begin{array}{c}\text { Bergantian Alat Sholat, } \\
\text { Tidak } \\
\text { Ya } \\
\end{array}$ & $\begin{array}{c}87(45.8) \\
103(54.2)\end{array}$ \\
\hline $\begin{array}{c}\text { Kebersihan Kulit, } \\
\text { buruk } \\
\text { baik }\end{array}$ & $\begin{array}{l}31(16.3) \\
159(83.7)\end{array}$ \\
\hline $\begin{array}{c}\text { Kebersihan Tangan, } \\
\text { buruk } \\
\text { baik }\end{array}$ & $\begin{array}{r}77(40.5) \\
133(59.5) \\
\end{array}$ \\
\hline $\begin{array}{c}\text { Kebersihan Pakaian, } \\
\text { buruk } \\
\text { baik }\end{array}$ & $\begin{array}{l}71(37.4) \\
119(62.6)\end{array}$ \\
\hline $\begin{array}{c}\text { Kebersihan Handuk, } \\
\text { buruk } \\
\text { baik }\end{array}$ & $\begin{array}{l}68(35.8) \\
122(64.2)\end{array}$ \\
\hline $\begin{array}{c}\text { Kebersihan Tempat Tidur, } \\
\text { buruk } \\
\text { baik }\end{array}$ & $\begin{array}{l}127(66.8) \\
63(33.2)\end{array}$ \\
\hline $\begin{array}{l}\text { Pengetahuan, } \\
\text { buruk } \\
\text { sedang } \\
\text { baik } \\
\end{array}$ & $\begin{array}{l}63(33.2) \\
77(40.5) \\
50(26.3) \\
\end{array}$ \\
\hline $\begin{array}{ll}\text { Skabies } & \\
& \text { ya } \\
& \text { tidak } \\
\end{array}$ & $\begin{array}{l}51(26.8) \\
139(73.2)\end{array}$ \\
\hline
\end{tabular}

Tabel 1 menunjukkan sebagian besar responden pada rentang usia 14-16 tahun (46.8\%), sebagian besar responen tidak saling bergantian pakaian ( $51.6 \%)$, sebagian besar responden bergantian alat sholat (54.2\%), sebagian besar responen memiliki kebersihan kulit yang baik $(83.7 \%)$, sebagian besar responden memiliki kebersihan tangan yang baik (59.4\%), memiliki kebersihan pakaian baik (62.6\%), tingkat kebersihan handuk baik (64.2\%). Mayoritas kebersihan tempat tidur responden dalam kategori buruk (66.8\%), tingkat pengetahuan sebagian besar responden dalam 
kategori sedang (40.5\%). Prevalensi scabies $26.8 \%$ (51 orang).

Tabel 2. Hubunganfaktor risiko dengan kejadian scabies

\begin{tabular}{|c|c|}
\hline Karakteristik sampel & OR ( $95 \% \mathrm{CI})$ \\
\hline $\begin{array}{l}11-16 \text { tahun } \\
>17 \text { tahun }\end{array}$ & $5.531(2.214-13.822)$ \\
\hline $\begin{array}{c}\text { Bergantian Pakaian, } \\
\text { Tidak } \\
\text { Ya }\end{array}$ & $0.869(0.457-1.652)$ \\
\hline $\begin{array}{c}\text { Bergantian Alat Sholat, } \\
\text { Tidak } \\
\text { Ya } \\
\end{array}$ & $1.072(0.564-2.040)$ \\
\hline $\begin{array}{c}\text { Kebersihan Kulit, } \\
\text { buruk } \\
\text { baik }\end{array}$ & $2.715(1.223-6.027)$ \\
\hline $\begin{array}{c}\text { Kebersihan Tangan, } \\
\text { buruk } \\
\text { baik }\end{array}$ & $2.499(1.296-4.812)$ \\
\hline $\begin{array}{c}\text { Kebersihan Pakaian, } \\
\text { buruk } \\
\text { baik }\end{array}$ & $1.740(0.906-3.341)$ \\
\hline $\begin{array}{c}\text { Kebersihan Handuk, } \\
\text { buruk } \\
\text { baik }\end{array}$ & $1.534(0.795-2.959)$ \\
\hline $\begin{array}{c}\text { Kebersihan Tempat Tidur, } \\
\text { buruk } \\
\text { baik }\end{array}$ & $3.519(1.538-8.052)$ \\
\hline $\begin{array}{l}\text { Pengetahuan, } \\
\text { Kurang baik } \\
\text { ( sedang - buruk ) } \\
\text { baik }\end{array}$ & $0.924(0.446-1.903)$ \\
\hline
\end{tabular}

Berdasarkan tabel 2 di dapatkan hasil yaitu, usia 11- 16 tahun meningkatkan risiko skabies 5.5 kali lebih besar dibandingkan usia $>17$ tahun $(\mathrm{OR}=5.531$, 95\% CI= 2.214-13.822), kebersihan kulit yang buruk meningkatkan risiko skabies 2.7 kali lebih besar dibandingkan kebersihan kulit yang baik $(\mathrm{OR}=2.715$, 95\% CI=1.223-6.027), Kebersihan tangan yang buruk meningkatkan risiko skabies 2.4 kali lebih besar di bandingkan kebersihan tangan yang baik $(\mathrm{OR}=2.499$, 95\% CI=1.296-4.812), Kebersihan tempat tidur yang buruk meningkat kan risiko skabies 3.5 kali lebih besar di bandingkan kebersihan tempat tidur yang buruk $(\mathrm{OR}=3.519,95 \% \mathrm{CI}=1.538-8.052)$,

\section{PEMBAHASAN}

A. Hubungan usia dengan Kejadian skabies

Dari hasil analisis di dapatkan usia 11- 16 tahun meningkatkan risiko skabies 5.5 kali lebih besar dibandingkan usia $>17$ tahun. Hal ini kemungkinan dikarenakan tingkat kesadaran akan kesehatan pada usia > 17 tahun lebih tinggi sehingga dapat melakukan upaya pencegahan.

Usia mempengaruhi daya tangkap dan pola pikir seseorang. Pengalaman keterpaparan scabies sebelumya menyebabkan seserang memiliki pengalaman terhadap skabies dan pengetahui penyebab dan upaya pencegahannya. ${ }^{7}$

B. Hubungan bergantian pakaian dengan kejadian skabies

Bergantian pakaian bukan merupakan faktor risiko kejadian scabies. Hal ini berbeda dengan penelitian sebelumnya yang menyatakan bergantian pakaian 2,9 kali meningkatkan risiko kejadian scabies. ${ }^{7}$ Perbedaan ini kemungkinan dikarenakan tingginya kesadaran santri pondok pesantren untuk tidak berganti-ganti pakaian dan tidak saling meminjam pakaian antar santri pondok pesantren.

C. Hubungan bergantian alat sholat dengan kejadian skabies

Bergantian alat sholat bukan merupakan faktor risiko kejadian scabies, hasil penelitian ini tidak sejalan dengan hasil penelitian sebelumnya yang menyatakan bergantian alat sholat berhubungan dengan kejadian skabies. ${ }^{8}$ Perbedaan hasil ini kemungkinan dikarenakan setiap santri menggunakan alat sholat sendiri-sendiri tanpa meminjam santri lain.

D. Hubungan kebersihan kulit dengan kejadian skabies 
Kebersihan kulit yang buruk meningkatkan risiko skabies 2.7 kali lebih besar dibandingkan kebersihan kulit yang baik. Penelitian ii serupa dengan penelitian sebelumnya yang menyatakan kebersihan kulit mempunyai resiko terhadap penyakit skabies 3,261 kali di bandingkan orang yang menjaga kebersihan kulit. ${ }^{9}$ Penelitian ini kemungkinan terjadi karena sebagian santri tidak memperhatikan kebersihan kulit mereka, hal ini juga dapat di pengaruhi oleh ketidaktahuan mereka bahwa penyebaran penyakit kulit khususnya skabies dapat terjadi melalui kontak kulit. Kondisi kulit yang lembab dan kebiasaan mandi $<2$ kali sehari juga dapat berkontribusi meningkatkan risiko terjadinya scabies.

E. Hubungan Kebersihan tangan dengan kejadian skabies

Kebersihan tangan yang buruk meningkatkan risiko skabies 2.4 kali lebih besar di bandingkan kebersihan tangan yang baik. Hasil ini serupa dengan penelitian lain yang menyatakan kebersihan tangan yang buruk meningkatkan risiko skabies sebesar 3,473 kali di bandingkan orang yang menjaga kebersihan tangan dengan baik, penelitian ini menunjukan bahwa sebagian responden tidak memperhatikan kebersihan tangan dan kuku sehingga mudah tertular scabies. ${ }^{10}$

Adanya tradisi cium tangan antara guru dan santri dan bersalam-salaman juga disinyalir dapat menjadi transmisi penularan scabies jika sesorang tidak menjaga kebersihan kulit khususnya tangan seperti rajin mencuci tangan.

F. Hubungan Kebersihan pakaian dengan kejadian skabies

Kebersihan pakaian bukan merupakan faktor risiko terjadinya scabies. Berbeda dengan penelitian sebelumnya yag menunjukan bahwa kebersihan pakaian yang kurang baik merupakan faktor yang risiko terhadap kejadian skabies pada santri $(\mathrm{OR}=4,062)$, Menjaga kebersihan pakaian dengan baik dapat menurunkan risiko santri untuk terkena skabies, pakaian berperan dalam transmisi tungau skabies melalui kontak tak langsung sehingga mempengaruhi kejadian skabies. ${ }^{10}$ kebiasaanya sering mencuci baju juga dapat menurunkan angka kejadian scabies.

G. Hubungan kebersihan handuk dengan kejadian skabies

Dari hasil analisis kebersihan handuk tidak meningkatkan risiko scabies. Hal ini terjadi karena sebagian besar santri sudah memakai handuk yang di pakai sendiri -sendiri, walaupun masih ada sebagian kecil santri dalam satu kamar masih menggunakan handuk bersama-sama.

Hasil tersebut tidak sejalan dengan penelitian sebelumnya oleh Parman (2017) yang menyatakan kebersihan handuk yang tidak baik meningkatkan risiko scabies dengan sebesar 4,316 kali di banding kan orang yang menjaga kebersihan handuk, hal ini di sebabkan oleh adanya kebiasaan santri menjemur handuk di dalam kamar, dan tidak semua santri memili alat mandi sendiri - sendiri, dan santri saling bergantian handuk. Sarcoptes scabei dapat bertahan hidup pada handuk dengan kondisi lembab. ${ }^{10}$

H. Hubungan kebersihan tempat tidur dengan kejadian skabies

Kebersihan tempat tidur yang buruk meningkatkan risiko skabies 3.5 kali lebih besar dibandingkan kebersihan tempat tidur yang buruk. Hal ini serupa dengan penelitian lain bahwa kebiasaan tidak menjaga kebersihan tempat tidur meningkatkan risiko skabies sebesar 5,009 kali di bandingkan orang yang menjaga kebersihan tempat tidur dikarenakan responden beranggapan 
bahwa kasur dan sprei masih bersih sehingga responden mencuci dan menjemur sprei > 2 minggu sekali. ${ }^{11}$ Dari hasil pengamatan pada saat pengambilan sampel, di dapatkan informasi santri sangat jarang mencuci mencuci sprei, dan beberapa santri tidur di kasur tanpa sprei. Hal ini sangat memungkinkan kasur menjadi tempat berkembang biak scabies.

I. Hubungan faktor pengetahuan dengan kejadian skabies

Tingkat pengetahuan bukan menjadi faktor risiko terjadinya scabies. Hasil ini serupa denga penelitian di RSU Anutapura Palu yang menyatakan tingkat pengetahuan buka merupakan factor risiko scabies $(\mathrm{OR}=1,358 ; 95 \% \mathrm{CI}=0,661$ 2,791). ${ }^{12}$ Hasil penelitian ini berbeda dengan penelitian pada tahun 2014 yang menyatakaan bahwa tingkat pengetahuan berhubungan dengan kejadian skabies $\quad(p=0.001 ; \quad R P=4.261) \quad$ di karenakan pengetahuan merupakan domain yang sangat penting untuk terbentuk nya tindakan seseorang, ${ }^{13}$

\section{KESIMPULAN}

Berdasarkan hasil penelitian yang telah dilakukan maka diambil kesimpulan bahwa :

A. Kebersihan tempat tidur 3.5 kali meningkatkan risiko terjadinya skabies pada Pondok Pesantren Konvensional dan Modern.

B. Kebersihan kulit 2.7 kali meningkatkan risiko terjadinya skabies pada Pondok Pesantren Konvensional dan Modern santri.

C. Kebersihan tangan 2.4 kali meningkatkan risiko terjadinya skabies pada Pondok Pesantren Konvensional dan Modern.

D. Usia 5.5 kali meningkatkan risiko terjadinya skabies pada Pondok Pesantren Konvensional dan Modern..

\section{DAFTAR PUSTAKA}

1. Siregar RS. Atlas berwarna saripati penyakit kulit (edisi kedua). Jakarta: EGC 2005;45-9

2. Djuanda A. Ilmu Penyakit Kulit dan KelaminFakultas Kedokteran Universitas Indonesia Jakarta; 2010

3. Soemirat J. Kesehatan lingkungan. Yogyakarta: Gadjah Mada University Press 2011.

4. Saad. Pengaruh faktor higiene perorangan terhadap kejadian skabies di Pondok Pesantren An-Najach Magelang Tesis FK UNDIP. Semarang.2008.

5. Khotimah KK. Hubungan sanitasi lingkungan dan hygiene perorangan dengan kejadian scabies di Pondok Pesantren Al- Bahroniyah Ngemplak Mranggen kabupaten Demak 2013.

6. Ratnasari AF, Sungkar S. Prevalensi scabies dan faktor-faktor yang berhubungan di Pesantren X, Jakarta Timur. eJKI Vol.2 No.1, April 2014. 2014; $7-12$

7. Riris N. Hubungan antara faktor pengetahuan dan perilaku dengan kejadian skebies di pondok pesantren Al-muayyad Surakarta;2010

8. Kustantie AM. Perilaku pencegahan penyakit terhadap kejadian skabies pada Santri di Pondok Pesantren Al- falah putra Pekanbaru; 2016

9. Frenki. Hubungan personal hygiene santri dengan kejadian penyakit kulit infeksi skabies dan tinjauan sanitasi lingkungan pesantren darel hikmah kota pekanbaru;2011

10. Parman. Faktor risiko hygiene perorangan santri terhadap kejadian penyakit kulit skabies di Pesantren Al Baqiyatushalihat Tanjung Jabung Barat. 2017;250-1.

11. Sajida A. Hubungan personal hygiene dan sanitasi lingkungan dengan keluhan penyakit kulit di Kelurahan Denai Kecamatan Medan;2012. 
12. ArrifudinA, Kurniawan H, Fitriani. Faktor risiko scabies di Rumah Sakit Umum Anutapura Palu. Medika tadulako, Jurnal Ilmiah Kedokteran Vol. 3; No. 3, September 2016, 40-59

13. Hilma U. Faktor- faktor yang mempengaruhi kejadian skabies di Pondok Pesantren Mlangi Nogotirto Gamping Sleman Yogyakarta. Jurnal kedokteran dan kesehataan Indonesia. 2014; Vol. 6, No. 3, 153-4. 